\title{
Osmolality of Distal Tubular Fluid in the Dog*
}

\author{
James R. Clapp † and Roscoe R. Robinson $\ddagger$ \\ (From the Department of Medicine, Duke University Medical Center, Durham, N.C.)
}

Renal micropuncture observations in rodents have demonstrated that the tubular fluid from early portions of the distal convoluted tubule is always hypotonic to plasma $(1,2)$. A limited number of observations have suggested that its hypotonicity is maintained along the entire distal tubule during water diuresis (1). In contrast, during hydropenia with or without a superimposed osmotic diuresis, the distal fluid achieves osmotic equilibrium with plasma in later portions of the distal tubule $(1,2)$. Consequently, in the presence of antidiuretic hormone, it has been widely accepted that distal tubular fluid is always isosmotic to plasma as it enters the cortical collecting ducts.

These findings in rodents have precluded a satisfactory explanation for the observation that man and dog can excrete hypotonic final urine during certain experimental and pathological conditions when antidiuretic hormone activity is presumably adequate (3-11). These observations have been most apparent at high rates of urine flow and solute excretion. If, as in the rat $(2,12)$, the tubular fluid of the dog is isosmotic as it enters the collecting ducts under these conditions, the subsequent excretion of hypotonic urine would require that the collecting ducts reabsorb solute in excess of water. Since this explanation is inconsistent with current concepts of solute and water reabsorption by the collecting ducts in the presence of maximal amounts of vasopressin (water in excess of solute), some investigators $(9,13,14)$ have

\footnotetext{
* Submitted for publication May 31, 1966; accepted August 19, 1966.

Supported by grants from the U. S. Public Health Service (AM 05930 and AM 07420), the American Heart Association, the Life Insurance Medical Research Fund, and the North Carolina Heart Association.

$\dagger$ Established Investigator of the American Heart Association.

Address requests for reprints to Dr. James R. Clapp, Dept. of Medicine, Duke University Medical Center, Durham, N. C. 27706.

$\ddagger$ Senior Investigator of the North Carolina Heart Association.
}

suggested that dog distal fluid is normally hypotonic rather than isotonic at the end of the distal convolution. If so, at high rates of urine flow during osmotic diuresis, the ability of the collecting ducts to abstract solute-free water might be so exceeded that hypotonic urine could be excreted despite the presence of antidiuretic hormone. Possible relationships among rates of solute excretion, vasopressin dosage, and solute-free water reabsorption by the collecting ducts have been discussed fully by Orloff, Wagner, and Davidson (11).

Heretofore, direct measurements of distal fluid osmolality utilizing micropuncture techniques have not been feasible in the dog because the distal convoluted tubules could not be recognized on the surface of the kidney (15). Renal micropuncture experiments in this species have therefore been confined to studies of proximal tubular function. However, in the present study, segments of the distal convoluted tubules have been identified on the surface of the kidney, thus permitting the application of renal micropuncture techniques to an evaluation of the contribution of distal nephron segments to urinary concentration and dilution in normal dogs. In contrast to earlier observations in rodents $(1,2)$ measurements of osmolality have demonstrated that the tubular fluid is markedly hypotonic along the entire length of the distal tubule during hydropenia as well as water diuresis.

\section{Methods}

Renal micropuncture experiments were performed on nine healthy mongrel dogs weighing from 8.2 to $14.5 \mathrm{~kg}$. Five dogs were examined during hydropenia and antidiuresis; four animals were evaluated during water diuresis. Anesthesia was induced by the iv administration of Pentothal sodium ( $25 \mathrm{mg}$ per $\mathrm{kg}$ ) ; thereafter small supplemental doses were administered as necessary. Respiration was maintained through a cuffed endotracheal tube via a Harvard respirator. The ventilatory rate was adjusted to maintain the blood $\mathrm{PCO}_{2}$ between 35 and $45 \mathrm{~mm}$ $\mathrm{Hg}$. The left kidney was exposed through a flank incision, and indwelling polyethylene catheters were inserted into both foreleg veins and the ureter of the 
experimental kidney. An additional polyethylene catheter was introduced into the abdominal aorta via a femoral artery to the approximate level of the renal arteries.

Dogs studied during antidiuresis were deprived of water after receiving an im injection of Pitressin tannate in oil ( $1 \mathrm{U}$ ) about 16 hours before the experiment. After the induction of anesthesia these animals received a single iv injection of aqueous vasopressin ( $33 \mathrm{mU}$ per $\mathrm{kg}$ ). A maintenance infusion of aqueous vasopressin in $5 \%$ dextrose in water ( $50 \mathrm{mU}$ per $\mathrm{kg}$ per hour, $0.25 \mathrm{ml}$ per minute) was administered via a foreleg vein throughout each experiment.

Animals examined during water diuresis were allowed free access to water before each study. After anesthesia, water diuresis was induced by the rapid iv administration of $2.5 \%$ dextrose in water ( 40 to $80 \mathrm{ml}$ per $\mathrm{kg}$ ). The initial water load was followed by a constant iv infusion of $2.5 \%$ dextrose in water at a rate equal to the urine flow. Water diuresis occurred within 3 to 7 hours. Qualitative tests for urinary glucose were negative during the entire period of water diuresis.

In each group, preparatory to micropuncture, the left kidney was immobilized on a Lucite holder as described previously (15). The administration of an initial priming dose of inulin was followed by a constant infusion $(0.3 \mathrm{ml}$ per minute $)$ of 2.5 to $5 \%$ inulin in either $5 \%$ dextrose in water (antidiuresis experiments) or $0.85 \%$ saline (water diuresis experiments). After equilibration of the priming dose of inulin, sequential renal clearance periods of 15 to 20 minutes' duration were obtained throughout each study. Heparinized samples of arterial blood were obtained at the midpoint of each urine collection period for the determination of the plasma inulin concentration and osmolality. Similar measurements were also performed on timed collections of urine from the experimental kidney.

A single sample of proximal fluid and two to nine samples of distal tubular fluid were obtained from the surface convolutions during each experiment. The technique for collection of proximal fluid samples and the means of identifying the sites of tubular puncture in this segment of the nephron have been described previously (15). The identification of surface convolutions of the distal tubule was facilitated by the intra-aortic injection of 1 or $2 \mathrm{ml}$ of $5 \%$ lissamine green before each distal puncture. After its injection the dye appeared rapidly in the peritubular circulation and proximal tubular fluid. Its passage through the lumina of the proximal convoluted tubules was usually complete within 20 to $25 \mathrm{sec}$ onds, at which time the surface of the kidney appeared completely devoid of dye. Approximately 30 to $50 \mathrm{sec}-$ onds later, the dye reappeared within the lumina of distal convoluted tubules. Visible dye disappeared completely from the surface of the kidney within 2 minutes after its injection. Samples of distal fluid were collected after the dye had disappeared completely from the distal tubular lumen. The total injected dose of lissamine green was kept as small as possible during each experiment, and each injection of dye was always separated by an interval of at least 7 to 10 minutes. In general, no more than a short segment of a single distal tubule extended to the kidney surface. The number of distal tubules on the surface of the kidney varied greatly from one animal to another, and none at all were observed on occasion. The diameter of the distal tubular lumen was usually smaller than that of the proximal tubule; occasionally, they were equal in size. The location of a single distal tubule had to be noted with great care during the passage of dye because the transparency of their epithelial lining made them difficult to see once the dye had cleared the distal tubular lumen. However, once a distal tubule had been identified and punctured, samples could be collected with relative ease because of a brisk flow of tubular fluid even during hydropenia. Sites of distal tubular puncture were identified by the latex injection and dissection technique (16). As in the rat, the distal convoluted tubule is defined as that segment of the distal nephron between the macula densa and the point at which it joins with another distal tubule to form a cortical collecting duct.

Before the collection of distal fluid samples, the direction of flow along the tubule was first ascertained by the injection of a droplet of colored mineral oil. Samples of tubular fluid (approximately $0.01 \mu \mathrm{l}$ ) were then collected at a rate sufficient to maintain the distal position of an injected oil droplet. Only a brief period of time was required for the collection of these small samples. Immediately after collection, the samples were emptied from the collection pipettes into a siliconized petri dish filled with hydrated mineral oil. Duplicate aliquots $(<0.001 \mu \mathrm{l})$ of the sample were transferred into separate mineral oil-filled quartz capillaries (i.d. $25 \mu$ ), and their osmolality was measured cryoscopically in an Advanced nanoliter osmometer. This apparatus permitted simultaneous measurements on the unknown sample and two standard solutions of known osmolality $(500,100$, or 50 mOsm per $\mathrm{kg}$ of $\mathrm{H}_{2} \mathrm{O}$ ). In this fashion, each of the duplicate readings was bracketed by simultaneous readings on two standard solutions of known osmolality. Ultramicro osmolality measurements on plasma samples from each experiment averaged $98.2 \%$ of the macro measurements on the same sample. Replicate ultramicro analyses on different aliquots of the same sample always agreed within $\pm 2 \%$.

Plasma and urinary inulin concentrations were determined by the anthrone method of Fuhr, Kaczmarczyk, and Kruttgen. Macro measurements of the osmolality of plasma and urine were made on an Advanced osmometer (model 64-31).

\section{Results}

Hydropenia and antidiuresis. Individual values from five experiments are tabulated separately in Table I. Plasma and urine osmolality averaged $308 \pm 3$ and $1,627 \pm 553 \mathrm{mOsm}$ per $\mathrm{kg}$ (SD), respectively. Urine flow from the single experimental kidney averaged $0.10 \pm 0.12 \mathrm{ml}$ per minute (SD). The unilateral clearance of inulin 
averaged $17 \pm 6 \mathrm{ml}$ per minute (SD) for all clearance periods.

Three samples of proximal fluid and 24 samples of distal fluid were obtained from the five dogs in this group (Table I, Figure 1). In agreement with previous observations in the dog during similar experimental conditions (15), the ratio between the osmolality of proximal fluid and that of plasma (osmolal TF/P ratio) approximated 1.0. In contrast, the distal fluid was markedly hyposmotic to plasma along the entire length of the distal convoluted tubule (Figure 1). The osmolality of distal fluid ranged from 56 to 217 mOsm per $\mathrm{kg}$, averaging $126 \pm 41 \mathrm{mOsm}$ per $\mathrm{kg}$ (SD) for all distal samples (average distal osmolal TF/P ratio, $0.41 \pm 0.13$ ). Once the tubular fluid had entered the early distal tubule, a further change in osmolality was not apparent along the length of the distal convoluted tubule (Figure 1). The average osmolal $\mathrm{TF} / \mathrm{P}$ ratio of eleven early distal samples ( 0 to $50 \%$ length) was $0.40 \pm 0.18$ (SD), and that of thirteen late distal samples ( 50 to $100 \%$ length) was $0.41 \pm 0.11$ (SD). In contrast, the average osmolal urine to plasma ratio was $5.3 \pm 2.1$ ( $\mathrm{SD}$ ).

Water diuresis. The individual values from these four experiments are also tabulated in Table I. The plasma osmolality was lower than that observed during antidiuresis, averaging $279 \pm 3$ mOsm per $\mathrm{kg}(\mathrm{SD})$. Urine osmolality averaged $131 \pm 45 \mathrm{mOsm}$ per $\mathrm{kg}$ (SD). Urine flow from the experimental kidney alone averaged $1.10 \pm$ $0.36 \mathrm{ml}$ per minute (SD). Inulin clearance by the single kidney was relatively stable during each experiment (Table I), averaging $21 \pm 6 \mathrm{ml}$ per minute (SD).

In agreement with previous observations (15), proximal tubular fluid was essentially isosmotic to plasma during water diuresis (average osmolal $\mathrm{TF} / \mathrm{P}$ ratio of four proximal samples, $0.98 \pm 0.02$; Figure 1). Nineteen samples of distal fluid were obtained (Table I, Figure 1). Again, distal fluid was markedly dilute along the entire length of the distal convoluted tubule. The average osmolal $\mathrm{TF} / \mathrm{P}$ ratio of all distal samples was $0.24 \pm 0.07$ (SD), a value that was significantly lower ( $\mathrm{p}<$ 0.001 ) than the average distal $\mathrm{TF} / \mathrm{P}$ ratio during hydropenia. The distal $\mathrm{TF} / \mathrm{P}$ ratio during water diuresis was also lower $(\mathrm{p}<0.001)$ than simultaneous measurements of the osmolal $\mathrm{U} / \mathrm{P}$ ra- tion (average, $0.47 \pm 0.19$ ). Further, tubular fluid appeared maximally dilute as it entered the distal convolution (average osmolal $\mathrm{TF} / \mathrm{P}$ ratio of eight samples of early distal fluid, $0.23 \pm 0.05$ (SD); average osmolal $\mathrm{TF} / \mathrm{P}$ ratio of eleven samples of late distal fluid, $0.24 \pm 0.07$ ).

\section{Discussion}

In contrast to previous renal micropuncture observations in rodents $(1,2)$, our data in the dog demonstrate clearly that the tubular fluid is markedly hypotonic throughout the surface segments of the distal convoluted tubule during hydropenia and antidiuresis. Osmotic equilibrium between distal tubular fluid and plasma was never achieved despite the presence of antidiuretic hormone in adequate amounts. As a result, the tubular fluid was always hypotonic as it entered the cortical collecting ducts. Comparison of these findings with previous observations in hydropenic rats (in which hypotonic early distal fluid becomes essentially isosmotic to plasma by the midportion of

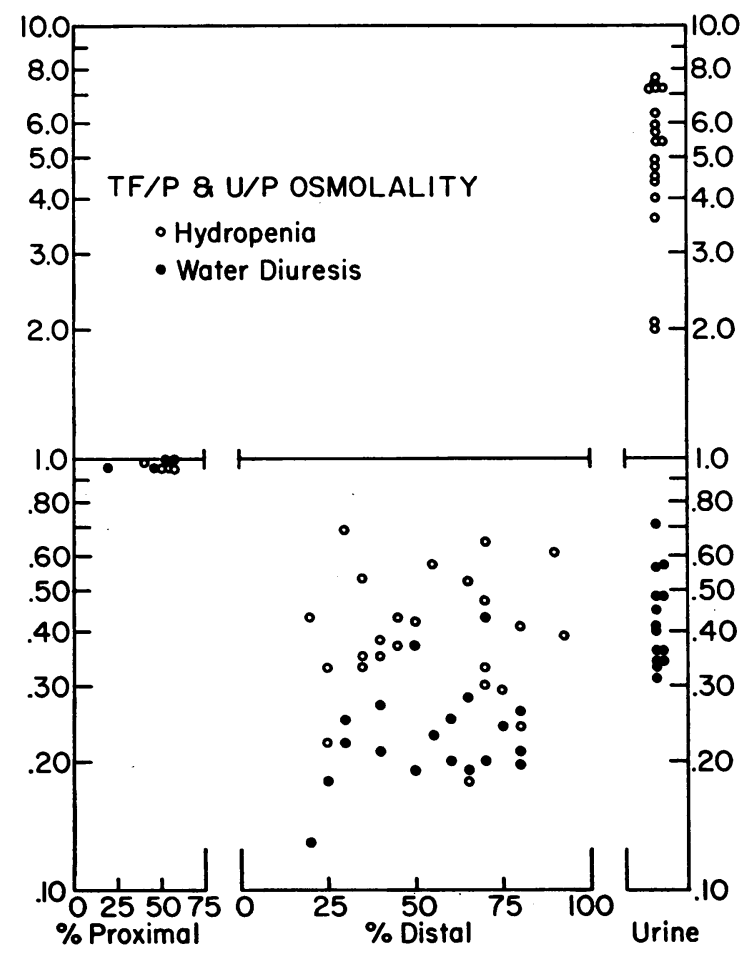

Fig. 1. Osmolal TF/P Ratios for proximal aNd DISTAL TUBULAR FLUID OF THE DOG DURING HYDROPENIA OR WATER DIURESIS. TF $/ \mathrm{P}=$ tubular fluid to plasma; $\mathrm{U} / \mathrm{P}=$ urine to plasma. 
TABLE I

Osmolality of proximal and distal tubular fluid of the dog during either antidiuresis or water diuresis*

\begin{tabular}{|c|c|c|c|c|c|c|c|c|c|}
\hline \multirow{2}{*}{$\begin{array}{l}\text { Dog } \\
\text { no. }\end{array}$} & \multirow{2}{*}{$\begin{array}{l}\text { Clear- } \\
\text { ance } \\
\text { period }\end{array}$} & \multirow[b]{2}{*}{ Location } & \multirow[b]{2}{*}{$C_{\text {In }}$} & \multirow[b]{2}{*}{$\mathbf{V}$} & \multicolumn{3}{|c|}{ Osmolality } & \multirow{2}{*}{$\underset{\mathrm{TF} / \mathrm{P}}{\text { Osmolal }}$} & \multirow{2}{*}{$\underset{U / P}{\text { Ratios }}$} \\
\hline & & & & & Plasma & TF & Urine & & \\
\hline & & \%length & $m l / m i n$ & $m l / m i n$ & & $m O s m / k g$ & & & \\
\hline \multicolumn{10}{|c|}{ A. Antidiuresis } \\
\hline \multirow[t]{4}{*}{30} & 1 & $\begin{array}{l}\text { D35 } \\
\text { D35 }\end{array}$ & 17 & 0.17 & 304 & $\begin{array}{l}160 \\
101\end{array}$ & 1,097 & $\begin{array}{l}0.53 \\
0.53\end{array}$ & 3.6 \\
\hline & 3 & D70 & 12 & 0.07 & 304 & 195 & 1,215 & 0.64 & 4.0 \\
\hline & 4 & D20 & 11 & 0.06 & 304 & 131 & 1,447 & 0.43 & 4.8 \\
\hline & $\begin{array}{l}5 \\
6\end{array}$ & $\begin{array}{l}\text { D40 } \\
\text { P40 }\end{array}$ & $\begin{array}{l}14 \\
11\end{array}$ & $\begin{array}{l}0.09 \\
0.07\end{array}$ & $\begin{array}{l}304 \\
304\end{array}$ & $\begin{array}{l}115 \\
298\end{array}$ & $\begin{array}{l}1,501 \\
1,372\end{array}$ & $\begin{array}{l}0.38 \\
0.98\end{array}$ & $\begin{array}{l}4.9 \\
4.5\end{array}$ \\
\hline 31 & 1 & D45 & 15 & 0.06 & 306 & 114 & 1,798 & 0.37 & 5.9 \\
\hline \multirow[t]{2}{*}{32} & 1 & D80 & 10 & 0.26 & 312 & 127 & 609 & 0.41 & 2.0 \\
\hline & & D90 & & 0.28 & 312 & 190 & 639 & 0.61 & 2.0 \\
\hline \multirow[t]{6}{*}{34} & 1 & $\begin{array}{l}\text { D75 } \\
\text { D25 }\end{array}$ & 24 & 0.09 & 305 & 89 & 2,194 & \multirow{6}{*}{$\begin{array}{l}0.29 \\
0.22 \\
0.33 \\
0.47 \\
0.24 \\
0.18 \\
0.42 \\
0.98\end{array}$} & 7.2 \\
\hline & 2 & $\begin{array}{l}\text { D70 } \\
\text { D70 }\end{array}$ & 21 & 0.07 & 310 & $\begin{array}{l}101 \\
145\end{array}$ & 2,254 & & 7.3 \\
\hline & 3 & D80 & 24 & 0.09 & 305 & 74 & 1,648 & & 5.4 \\
\hline & 4 & D65 & 15 & 0.07 & 308 & 56 & 1,343 & & 4.4 \\
\hline & 5 & D50 & 24 & 0.07 & 310 & 131 & 1,664 & & 5.4 \\
\hline & & P55 & & & & 305 & & & \\
\hline \multirow[t]{7}{*}{35} & 1 & $\begin{array}{l}\text { D35 } \\
\text { D90 }\end{array}$ & 29 & 0.08 & 314 & \multirow{7}{*}{$\begin{array}{r}110 \\
121 \\
134 \\
180 \\
217 \\
111 \\
297 \\
104 \\
93 \\
162\end{array}$} & 2,258 & \multirow{7}{*}{$\begin{array}{l}0.35 \\
0.39 \\
0.43 \\
0.57 \\
0.69 \\
0.35 \\
0.95 \\
0.33 \\
0.30 \\
0.52\end{array}$} & 7.2 \\
\hline & 2 & D45 & 21 & 0.05 & 314 & & 1,979 & & 6.3 \\
\hline & 3 & $\begin{array}{l}\text { D55 } \\
\text { D30 }\end{array}$ & 23 & 0.07 & 314 & & 2.384 & & 7.6 \\
\hline & & D40 & & & & & & & \\
\hline & 4 & P55 & 14 & 0.05 & 314 & & 2,250 & & 7.2 \\
\hline & & D25 & & & & & & & \\
\hline & & $\begin{array}{l}\text { D70 } \\
\text { D65 }\end{array}$ & & & & & & & \\
\hline \multicolumn{10}{|c|}{ B. Water diuresis } \\
\hline \multirow[t]{7}{*}{42} & 1 & D50 & 19 & 1.64 & 284 & 106 & 89 & \multirow{7}{*}{$\begin{array}{l}0.37 \\
0.23 \\
0.19 \\
0.25 \\
0.21 \\
0.28 \\
0.26 \\
1.01\end{array}$} & 0.31 \\
\hline & 2 & D55 & 13 & 1.53 & 282 & 65 & 97 & & 0.34 \\
\hline & & D65 & & & & 53 & & & \\
\hline & 3 & $\begin{array}{l}\text { D60 } \\
\text { D40 }\end{array}$ & 17 & 1.30 & 284 & $\begin{array}{l}72 \\
60\end{array}$ & 115 & & 0.40 \\
\hline & 4 & D65 & 18 & 1.00 & 281 & 80 & 136 & & 0.48 \\
\hline & 5 & D80 & 23 & 0.73 & 280 & 72 & 158 & & 0.56 \\
\hline & 6 & P50 & 20 & 0.60 & 280 & 283 & 255 & & 0.91 \\
\hline \multirow[t]{5}{*}{43} & 1 & D50 & 18 & 1.23 & 278 & 53 & 114 & \multirow{5}{*}{$\begin{array}{l}0.19 \\
0.27 \\
0.24 \\
0.25 \\
0.43 \\
1.00\end{array}$} & 0.41 \\
\hline & 2 & $\begin{array}{l}\text { D40 } \\
\text { D75 }\end{array}$ & 21 & 1.40 & 278 & $\begin{array}{l}75 \\
67\end{array}$ & 100 & & 0.36 \\
\hline & 3 & D30 & 23 & 1.53 & 279 & 71 & 96 & & 0.34 \\
\hline & 5 & D70 & 17 & 1.27 & 280 & 120 & 94 & & 0.33 \\
\hline & & P55 & & & & 281 & & & \\
\hline 46 & 1 & $\begin{array}{l}\text { D30 } \\
\text { D20 }\end{array}$ & 19 & 1.07 & 278 & $\begin{array}{l}61 \\
35\end{array}$ & 101 & 0.22 & 0.36 \\
\hline & 2 & P45 & 16 & 0.50 & 278 & 260 & 134 & $\begin{array}{l}0.13 \\
0.94\end{array}$ & 0.48 \\
\hline 47 & 1 & D60 & 28 & 1.10 & 278 & 56 & 124 & 0.20 & 0.45 \\
\hline & & D80 & & & & 58 & & 0.21 & \\
\hline & 2 & $\begin{array}{l}\text { D25 } \\
\text { D80 }\end{array}$ & 34 & 0.90 & 277 & $\begin{array}{l}50 \\
54\end{array}$ & 158 & $\begin{array}{l}0.18 \\
0.20\end{array}$ & 0.57 \\
\hline & 3 & $\begin{array}{l}\text { D70 } \\
\text { P20 }\end{array}$ & 33 & 0.63 & 274 & $\begin{array}{r}55 \\
259\end{array}$ & 195 & $\begin{array}{l}0.20 \\
0.95\end{array}$ & 0.71 \\
\hline
\end{tabular}

* Abbreviations: $\mathrm{C}_{\mathrm{In}}=$ inulin clearance; $\mathrm{V}=$ urine flow $\mathrm{TF} / \mathrm{P}=$ tubular fluid to plasma $\mathrm{U} / \mathrm{P}=$ urine to plasma $\mathrm{D}=$ distal; $\mathrm{P}=$ proximal. Values for inulin clearance, urine flow, and urine osmolality are those for the experimental kidney alone. 
the distal tubule) suggests strongly that the distal convoluted tubule of the dog is much less permeable to water than that of the rat. Thus, in the dog as opposed to the rat, that portion of the nephron which is relatively impermeable to water during antidiuresis must be extended to include the distal convoluted tubule as well as the ascending limb of the loop of Henle. However, in addition, it must be acknowledged that more efficient solute extraction by the distal tubular epithelium of the dog could contribute to the observed appearance of hypotonic distal fluid.

If volume reduction occurs along the length of the distal convolution during antidiuresis, as seems likely, the maintenance of similarly hypotonic fluid along its entire length suggests that the material reabsorbed which is removed by this nephron segment is hyposmotic to plasma; net solute and water removal occur in proportional amounts. The apparent absence of a progressive rise in osmolality demonstrates that the distal convoluted tubule of the dog does not contribute to the eventual osmotic concentration of the hypotonic fluid that leaves the thick ascending limb of the loop of Henle. The actual osmotic concentration of tubular fluid is an exclusive function of the collecting duct. However, it is possible that a small but physiologically significant rise of osmolality along the distal convolution could have been obscured by the scatter that individual collections from different nephrons impart to micropuncture data.

Observations during nephron microdissection in our laboratory have shown that the collecting ducts are formed by the junction of two or more superficial distal tubules near the surface of the renal cortex. As the collecting duct descends through the outer one-half of the cortex toward the renal medulla, it is joined by an additional four or five distal tubules from deeper nephrons. More than eight distal tubules rarely contribute to the formation of a single cortical collecting duct. The newly formed collecting duct descends straight through the inner one-half of the cortex where it is seldom joined by additional distal tubules. It is important to recognize that a significant segment of collecting duct passes through the renal cortex before it enters the hypertonic environment of the renal medulla.

The present experiments do not identify the site along the collecting duct at which the tubular fluid becomes at least transiently isosmotic to plasma as its osmotic concentration rises toward that of hypertonic final urine. Recognition of this site is important to the precise anatomic localization of solute-free water reabsorption $\left(\mathrm{T}^{\mathrm{c}} \mathrm{H}_{2} \mathrm{O}\right)$ during antidiuresis. If the tubular fluid becomes isosmotic to plasma within the cortical collecting duct (in which case the collecting duct fluid will presumably be isosmotic to plasma as it enters the renal medulla), the entire length of the medullary collecting duct would be expected to contribute to $\mathrm{T}^{\mathrm{c}}{ }_{\mathrm{H}_{2} \mathrm{O}}$ formation in the $\mathrm{dog}$ as in the rat. In this event, estimates of solute-free water removal should closely parallel directional alterations of solute removal by the entire medullary portion of the ascending limb of the loop of Henle. On the other hand, if osmotic equilibrium between cortical collecting duct fluid and plasma is not achieved so that hypotonic fluid enters the medullary collecting duct, it is certain that medullary collecting duct fluid will not become isosmotic to plasma until it has passed an undetermined distance into the medulla. Consequently, the entire length of the medullary collecting duct would not contribute to the formation of $\mathrm{T}^{\mathrm{c}}{ }_{\mathrm{H}_{2} \mathrm{O}}$. Nevertheless, changes in the reabsorption of solute-free water should still provide a qualitative index of solute removal by the ascending limb of the loop of Henle. Present data in the dog do not permit a definite statement as to whether $\mathrm{T}_{\mathrm{H}_{2} \mathrm{O}}$ formation is a function of the entire medullary collecting duct or only its more terminal portions.

If osmotic equilibrium with plasma is not achieved within the cortical collecting duct, the entry of a larger volume of hypotonic fluid into the renal medulla would also favor the subsequent reabsorption of a larger volume of dilute fluid from the collecting duct during the process of urinary concentration. Such an event would not only tend to interfere with the production of a maximally hypertonic medullary interstitium, but it might provide a partial explanation for the fact that the maximal concentrating ability of the dog is lower than that of the rat.

The finding that distal tubular fluid is even more dilute during water diuresis is of considerable interest. Since sodium (and its attendant anions) and urea are the major osmotically active solutes in distal tubular fluid, it is likely that the observed reduction in osmolality during water diuresis can 
be attributed to a reduced concentration of one or both of these solutes. If so, a reduced urea or sodium concentration in distal fluid could occur, either completely or in part, via at least four possible mechanisms. First, a reduced urea concentration could simply reflect a diminished net addition of urea to the fluid of the loop of Henle because of a lower urea concentration in the medullary interstitium. Second, a reduced sodium concentration in distal fluid could be the consequence of an increased delivery of sodium to the ascending limb of Henle's loop if water diuresis is accompanied by a diminished fractional reabsorption of sodium by the proximal tubule as suggested by previous renal micropuncture studies (15). A lower sodium concentration could then be attributed to increased sodium reabsorption in excess of water by the ascending limb of the loop of Henle and the distal tubule. Third, a reduced sodium concentration in the medullary interstitium secondary to an increased medullary blood flow during water diuresis might also contribute to the lower osmolality of distal fluid by reducing the concentration gradient against which sodium reabsorption must occur from the ascending limb of Henle's loop. Fourth, the diminished osmolality of early distal fluid could reflect a diminished permeability to water of the tubular epithelium of the ascending limb of the loop of Henle and the distal tubule. A reduction in the amount of circulating antidiuretic hormone would provide the most logical explanation for such a change in water permeability. If so, the entrance of more dilute tubular fluid into the early distal tubule during water diuresis would suggest that the site of action of antidiuretic hormone includes the ascending limb of the loop of Henle. The present data do not establish the actual importance of any of these four possibilities.

The demonstration of a higher osmolality in ureteral urine than that observed at the end of the distal tubule during water diuresis differs from previous observations in rodents (1). In itself, this observation suggests that water is removed in excess of solute from the collecting duct even during water diuresis, an observation that is compatible with the known existence of a slightly hypertonic medullary interstitium during water diuresis (17). However, since the present studies were not carried out during maximal water diu- resis, the higher osmolality in ureteral urine could be explained by an incomplete inhibition of antidiuretic hormone secretion and its continuing effect on the permeability of the collecting duct to water. Since only the surface convolutions of the distal tubule are accessible to micropuncture, one cannot exclude the possibility that the higher osmolality of ureteral urine may have resulted from the admixture of tubular fluid from deeper nephrons where the osmolality may have been higher than that in superficial nephrons.

Regardless of the exact mechanism by which the dog achieves and maintains a hypotonic tubular fluid throughout the entire distal tubule during both antidiuresis and water diuresis, the data do provide an adequate explanation for previous observations on the excretion of hypotonic final urine at high rates of solute excretion in the presence of adequate amounts of antidiuretic hormone (3-11). Under such conditions, the entrance of a larger volume of hypotonic distal fluid into the collecting duct could so exceed its ability to abstract solute-free water that hypotonic final urine would be excreted.

\section{Summary}

Surface segments of the distal convoluted tubule were identified in the dog, thus permitting the first application of renal micropuncture techniques to an investigation of distal nephron function in this species.

The osmolality of distal tubular fluid was measured either during hydropenia and antidiuresis or water diuresis to evaluate the contribution of distal nephron segments to urinary concentration and dilution. In contrast to previous micropuncture observations in rodents, the distal tubular fluid was found to be markedly dilute along the entire length of the distal tubule during both antidiuresis (average osmolal tubular fluid to plasma ratio, $0.41 \pm 0.13$ ) and moderate water diuresis (average osmolal tubular fluid to plasma ratio, $0.24 \pm 0.07)$. Despite the presence of adequate antidiuretic hormone, osmotic equilibrium between tubular fluid and plasma was never achieved at any site along the distal tubule.

We conclude that the water-impermeable segment of the dog nephron during antidiuresis must include the ascending limb of Henle's loop and the entire distal tubule. The normal entrance of hy- 
potonic tubular fluid into the cortical collecting duct provides a satisfactory explanation for previous observations on the excretion of hypotonic final urine at high rates of solute excretion in the $\operatorname{dog}$ (and perhaps in man) despite the presence of antidiuretic hormone in adequate amounts.

\section{Acknowledgments}

The authors are indebted to Dr. Karl Heinz Gertz for his demonstration of the use of lissamine green and to Constance Jenkins and Glenn Sides for their technical assistance.

\section{References}

1. Wirz, H. The location of antidiuretic action in the mammalian kidney in The Neurohypophysis, Proceedings of the Eighth Symposium of the Colston Research Society, H. Heller, Ed. New York, Academic Press, 1957, p. 157.

2. Gottschalk, C. W., and M. Mylle. Micropuncture study of the mammalian urinary concentrating mechanism: evidence for the countercurrent hypothesis. Amer. J. Physiol. 1959, 196, 927.

3. Levinsky, N. G., D. G. Davidson, and R. W. Berliner. Changes in urine concentration during prolonged administration of vasopressin and water. Amer. J. Physiol. 1959, 196, 451.

4. Zak, G. A., C. Brun, and H. W. Smith. The mechanism of formation of osmotically concentrated urine during the antidiuretic state. J. clin. Invest. 1954, 33, 1064.

5. Gill, J. R., Jr., and F. C. Bartter. On the impairment of renal concentrating ability in prolonged hypercalcemia and hypercalciuria in man. J. clin. Invest. 1961, 40, 716.

6. Giebisch, G., and R. Lozano. The effects of adrenal steroids and potassium depletion on the elaboration of an osmotically concentrated urine. J. clin. Invest. 1959, 38, 843.
7. Epstein, F. H., D. Beck, F. A. Carone, H. Levitin, and A. Manitius. Changes in renal concentrating ability produced by parathyroid extract. J. clin. Invest. 1959, 38, 1214.

8. Cohen, S. I., M. G. Fitzgerald, P. Fourman, W. J. Griffiths, and H. E. de Wardener. Polyuria in hyperparathyroidism. Quart. J. Med. 1957, 50, 423.

9. Goldsmith, C., H. K. Beasley, P. J. Whalley, F. C. Rector, Jr., and D. W. Seldin. The effect of salt deprivation on the urinary concentrating mechanism in the dog. J. clin. Invest. 1961, 40, 2043.

10. Earley, L. E., M. Kahn, and J. Orloff. The effects of infusions of chlorothiazide on urinary dilution and concentration in the dog. J. clin. Invest. 1961, 40, 857.

11. Orloff, J., H. M. Wagner, Jr., and D. G. Davidson. The effect of variations in solute excretion and vasopressin dosage on the excretion of water in the dog. J. clin. Invest. 1958, 37, 458.

12. Bank, N., and H. S. Aynedjian. On the mechanism of hyposthenuria in hypercalcemia. J. clin. Invest. $1965,44,681$.

13. Stein, R. M., B. H. Levitt, M. H. Goldstein, J. G. Porush, G. M. Eisner, and M. F. Levitt. The effects of salt restriction on the renal concentrating operation in normal, hydropenic man. J. clin. Invest. 1962, 41, 2101.

14. Thurau, K., and P. Deetjen. Die Diurese bei arteriellen Drucksteigerungen. Pflügers Arch. ges. Physiol. 1962, 274, 567.

15. Clapp, J. R., J. F. Watson, and R. W. Berliner. Osmolality, bicarbonate concentration, and water reabsorption in proximal tubule of the dog nephron. Amer. J. Physiol. 1963, 205, 273.

16. Rector, F. C., Jr., and J. R. Clapp. Evidence for active chloride reabsorption in the distal tubule of the rat. J. clin. Invest. 1962, 41, 101.

17. Levitin, H., A. Goodman, G. Pigeon, and F. H. Epstein. Composition of the renal medulla during water diuresis. J. clin. Invest. 1962, 41, 1145.

\section{SPECIAL NOTICE TO SUBSCRIBERS}

Post Offices will no longer forward the Journal when you move.

Please notify The Journal of Clinical Investigation, Business Office, 10 Stoughton. Street, Boston, Mass. 02118, at once when you have a change of address, and do not omit the Zip Code number. 